\title{
MANUEL SAMANIEGO TRAS LA CAUSA POR ADULTERIO: LA RECUPERACIÓN DE SU ACTIVIDAD EN LA REAL AUDIENCIA DE QUITO (1798-1811)
}

\author{
MANUEL SAMANIEGO AFTER THE TRIAL FOR \\ ADULTERY: THE RECOVERY OF HIS ACTIVITY IN THE \\ REAL AUDIENCIA DE QUITO (1798-1811)
}

\author{
Ángel Justo Estebaranz \\ Universidad de Sevilla. España \\ ORCID: 0000-0002-0837-8855 \\ ajestebaranz@us.es
}

\begin{abstract}
En el último lustro del siglo XVIII, el pintor quiteño Manuel Samaniego vivió un episodio turbio, teniendo que hacer frente a una causa por adulterio que había promovido su esposa, y que supuso su ingreso en la cárcel. Pero el maestro no vio truncada su carrera tras este suceso, sino que fue capaz de sobreponerse y continuarla con gran éxito. En este artículo nos acercamos a la situación que vivió Samaniego en los años posteriores a su encarcelamiento por adulterio. A través de documentación notarial y de referencias de autores coetáneos como Humboldt, Caldas y Stevenson estudiamos la vuelta a la normalidad de la vida del artista a nivel laboral y familiar, y su consideración como el artista más reconocido y valioso en el Quito de la época.

Palabras clave: Manuel Samaniego; Quito; pintura; catedral de Quito; Carondelet.
\end{abstract}

In the last years of the $18^{\text {th }}$ century, the Quito painter Manuel Samaniego experienced a turbulent episode, being involved in a case of adultery that his wife had promoted, and which meant his entry into prison. But the master did not see his career truncated after this event, but he was able to overcome and continue with great success. In this paper we approach the situation that Samaniego experienced in the years after his imprisonment for adultery. Through notarial documentation and references from contemporary authors such as Humboldt, Caldas and Stevenson, we study the back to normal of the artist's work and family life, and his consideration as the most recognized and valuable artist in Quito at the time.

Keywords: Manuel Samaniego; Quito; painting; Quito Cathedral; Carondelet. 


\section{RETOMANDO LA ACTIVIDAD TRAS LA CAUSA POR ADULTERIO: COCHICARANQUI Y LA CATEDRAL DE QUITO}

En 1797, cuando contaba unos 30 años de edad, el pintor quiteño Manuel Samaniego y Jaramillo se vio envuelto en un proceso por adulterio. Casado con doña Manuela Jurado López de Solís, el artista tuvo una relación con Josefa Yepes, mujer que estaba acogida en el monasterio de Santa Clara en la época en que Samaniego dirigía las obras de construcción del tabernáculo de la iglesia conventual. Enterada del asunto, la esposa interpuso una demanda que supuso el ingreso de los amantes en la cárcel, y la causa se prolongó hasta comienzos de $1798^{1}$. Recién salido de la cárcel, Manuel Samaniego hubo de retomar la actividad al frente de su obrador. La estrategia de su abogado, que hacía ver la necesidad de su puesta en libertad por dirigir a un importante grupo de pintores que necesitaban de su supervisión para llevar a cabo exitosamente los múltiples encargos que tenía, no era una argucia inventada, sino que se fundaba en la realidad. El artista tenía comprometida obra en varias poblaciones de la Real Audiencia de Quito y también en el exterior, tal como se relata en la causa por adulterio. Concretamente, se señalaba que estaban a su cargo varias obras que debía entregar "con prontitud" a Santa Fe de Bogotá, Lima, Guayaquil y otros lugares². Además, se incidía en que Samaniego era en estos momentos un oficial público bien acreditado "en las artes liberales de pintura y escultura". Pero no solo se encargó Samaniego de estas labores, pues en años inmediatamente posteriores lo encontramos realizando trabajos propios de un agrimensor, así como diseñando monumentos efímeros que trascendían la propia condición de pintor ${ }^{3}$.

El primer trabajo del que tenemos constancia en estos momentos data de diciembre de 1798. El día 6, el doctor don Manuel Salvador, abogado de la Real Audiencia y regidor perpetuo del Ayuntamiento de Quito, firmaba en esta ciudad un documento de fianza en favor de Manuel Samaniego ${ }^{4}$. El abogado reconocía estar al tanto de la causa por adulterio contra el pintor. A pesar de ello, se constituía

1 ANE (Archivo Nacional del Ecuador), sección Criminales, caja 171, expediente 9. La causa está analizada en JUSTO ESTEBARANZ, Ángel: “¿"Con mera salutacion o politica» o «ilicitamente a toda su satisfacción»?: La causa por adulterio contra Manuel Samaniego", Laboratorio de Arte, 24, 2012, pp. 453-472.

2 ANE, sección Criminales, caja 171, expediente 9, f. 28v.

${ }^{3}$ Samaniego no fue el único artista polifacético que trabajó en el Quito de la segunda mitad del siglo XVIII, pues otros como Bernardo Legarda o su hermano Juan Manuel también desarrollaron trabajos artísticos en la capital de la Real Audiencia. Véase KENNEDY TROYA, Alexandra: "Transformación del papel de talleres artesanales quiteños en el siglo XVIII. El caso de Bernardo Legarda", Anales del Museo de América, 2, 1994, p. 68; y KENNEDY TROYA, Alexandra: "Circuitos artísticos interregionales: de Quito a Chile. Siglos XVIII-XIX”, Historia, 31, 1998, p. 102.

${ }^{4}$ ANE, sección Protocolos Notariales, $6^{\mathrm{a}}$ Notaría, vol. 117, ff. 2v-3r (tachado 31). 
en su fiador y llano abonador. La razón de esta fianza estribaba en la intención de que el artista pudiera trasladarse a la hacienda Cochicaranqui para trazar un plano, diseño o mapa de los sitios que se le señalasen. Mediante esta fianza, a Samaniego se le otorgaría el permiso para su traslado y residir en la hacienda mencionada, pero solamente los días precisos y necesarios para llevar a cabo su cometido -que no se especifican en el documento-. Una vez terminada su labor, el artista tendría que regresar a Quito inmediatamente para "cumplir con lo que tiene prometido, y que no haga falta a la continuación de la d[ic]ha causa". Las últimas provisiones y notificaciones por el juicio conservadas en el expediente del Archivo Nacional del Ecuador datan de enero-febrero de 1798, casi un año antes de la fianza para el traslado de Samaniego a Cochicaranqui ${ }^{5}$. Ello hace suponer que el propietario de esta hacienda, o al menos su apoderado, debía de estar al tanto de las habilidades de Samaniego como agrimensor, pues aun estando reciente la causa por adulterio quiso contar con él y no con otro para llevar a cabo la realización del plano. Quizás ya antes hubiese desarrollado labores relacionadas con la agrimensura, y eso permitiera que se contactase con él aun a sabiendas de que sus problemas con los tribunales no habían terminado.

Resulta de interés enmarcar la actividad de Samaniego como agrimensor con la situación en la Real Audiencia de Quito. Según Capello, la época entre la misión geodésica francesa y la llegada de Humboldt supuso una era de patrocinio científico "por parte de la corona borbónica como parte de su programa de modernización imperial". Pero en el campo cartográfico, había una falta de técnicos avanzados, sobre todo de agrimensores, así como de dibujantes expertos, matemáticos e impresores ${ }^{6}$. Humboldt llegaría a Quito el 6 de enero de $1802^{7}$. Es decir, más de tres años después de la petición de desplazamiento de Samaniego a Cochicaranqui. Quizás por esto se encargasen de labores de agrimensura algunos pintores con nociones de la disciplina, y entre ellos a Samaniego.

En torno al cambio de siglo, la imagen de Manuel Samaniego debía de estar completamente restituida entre las élites quiteñas, tanto civiles como religiosas, pues ambas le hicieron encargos de gran importancia. Por ejemplo, sabemos que el artista quiteño trabajó para el marqués de Selva Alegre, para quien pintó una galería en su casa de campo ${ }^{8}$. Según Vargas, para la casa de hacienda del marqués pintó las alegorías de las Estaciones. Este encargo coincidió en el tiempo con la

${ }^{5}$ ANE, sección Criminales, caja 171, expediente 9, ff. 41r-42r.

${ }^{6}$ CAPELLO, Ernesto: "Cartógrafos y clérigos. Misiones geodésicas y religiosas en el conocimiento geográfico del Ecuador (Siglos XVIII-XX)", Araucaria. Revista Iberoamericana de Filosofía, Política y Humanidades, 24, 2010, p. 158.

${ }^{7}$ KLENCKE, Hermann y SCHLESIER, Gustav: Lives of the Brothers Humboldt: Alexander and William. London, 1852, p. 77.

${ }^{8}$ SUÁREZ, José Bernardo: Plutarco del Joven Artista. Tesoro de Bellas Artes. Santiago de Chile, 1872, p. 353. 
causa por adulterio, pues en la misma se indicaba expresamente que estaba concluyendo la obra en la casa preparada para el señor regente, y que este trabajo no podían hacerlo sus oficiales sin su supervisión ${ }^{9}$. Asimismo, la Casa Jijón le encargó la realización de retratos de personajes de la familia ${ }^{10}$. Estos encargos lo muestran como un artista apreciado como retratista, pero también como autor de valía en otros géneros.

Junto a los encargos de las élites civiles, el obrador de Samaniego recibió otros importantes provenientes de la Iglesia. Ya antes de la causa por adulterio, el artista había trabajado para alguna de las grandes órdenes religiosas establecidas en Quito. Concretamente, para el monasterio de Santa Clara, y para el edificio de la Compañía de Jesús gestionado por la Junta de Temporalidades, que en 1792 le abonaba 42 pesos por diversos trabajos ${ }^{11}$. Asimismo, el pintor quiteño fue contratado para trabajar en la catedral a fines de siglo. En sesión del 16 de noviembre de 1799, como vicepatrono de la catedral, el presidente de la Real Audiencia de Quito, barón de Carondelet, proponía al cabildo la construcción de un monumento "de buena talla y buen gusto, con las debidas proporciones para colocarse en la capilla que se había destinado para el efecto, en el Jueves Santo". El cabildo aceptó la propuesta, siempre que se comenzase y concluyera "a dirección del Presidente", y con la mayor brevedad y economía, para que pudiese servir en la siguiente Semana Santa ${ }^{12}$. El monumento, que se encargó a Samaniego, se realizó entre 1799 y 1800, según el historiador José Gabriel Navarro ${ }^{13}$. Constaba de seis telones "de menor a mayor y que guardan proporción", el primero de ellos de cuatro varas de alto y más de una de ancho, y el último de tres varas de alto y poco más de una de ancho. En el primer telón figuraban "una efigie en talla pintada representando a S. Juan Evangelista y a S. Mateo. Al pie del último arco a cada extremo un Judío sentado de vara de alto y media de ancho; delante de las dos columnas que lo componen un Profeta en pie" -en total, doce: Isaías, Jeremías, Ezequiel, Daniel, Habacuc, Malaquías, Zacarías, Sofonías, Ageo, Miqueas

9 NAVARRO, José Gabriel: La pintura en el Ecuador del XVI al XIX. Quito, 1991, p. 139.

10 VARGAS, José María: El arte ecuatoriano. Quito, 1960, p. 224.

${ }^{11}$ Concretamente, la pintura de los corredores altos de la Universidad, puertas, así como la composición de los 39 cuadros sobre la vida de San Francisco Javier. A ellos sumaba 4 pesos y 2 reales por las alcayatas y clavazón para fijar las pinturas de la serie. El recibo está reproducido y transcrito en VÁSQUEZ HAHN, María Antonieta: Luz a través de los muros. Biografía de un edificio quiteño. Quito, 2005, pp. 184-185. Asimismo, el artista quiteño también se encargó de la refacción de la pintura del salón de actos, o "General", de la Universidad.

${ }^{12}$ El documento, perteneciente a las actas capitulares correspondientes a la sesión del 26 de noviembre de 1799, está reproducido en NAVARRO, José Gabriel: Contribuciones a la Historia del Arte en el Ecuador. Vol. 4. 2a ed. revisada. Quito, 2007, p. 123.

13 NAVARRO, José Gabriel: Contribuciones..., op. cit., p. 124. 
y David, más Moisés- ${ }^{14}$. El monumento se armaba con las andas de plata del Santísimo. Asimismo, figuraban dos ángeles de madera pintada, un sol con rayos, un par de colgaduras de lienzo pintado, un castillo, una colgadura de cinco varas y tres cuartos de ancho que representaba "un hermoso pórtico", y un par de colgaduras pintadas con muchas almenas y estatuas para los lados del monumento ${ }^{15}$. En esta obra, Samaniego tuvo que trabajar coordinando a diversos profesionales -carpinteros, oficiales doradores y moledores de pintura y peones-. En la documentación se indica específicamente que se encargó de la inspección de la obra.

El cobro por el trabajo de Samaniego en el monumento se dilató unos años. En abril de 1802 escribía Francisco Rodríguez Soto - canónigo magistral de la catedral $^{16}$ - al presidente de la Real Audiencia de Quito, informándole sobre el trabajo del artista en el monumento del Jueves Santo ${ }^{17}$. El sacerdote trataba acerca del coste de la pintura del monumento a cargo de Samaniego, que le había pasado al presidente para que le diera su parecer. Este ascendía a 401 pesos y 2 reales, que estimaba "arreglado y en términos de nada exorbitante", a excepción de que el pintor declaraba haber recibido esta cantidad "por su mero trabajo e inspección en la obra", y quería 100 pesos más. El canónigo no creía justo este aumento, pues el dinero abonado ya le parecía "bien pagado". Recibida la carta, el mismo día le respondía el presidente Carondelet, señalando que el reclamo que hacía Samaniego de 100 pesos más por el costo y hechura de las piezas del monumento no era justo, por lo que no se le debía pagar más que lo ya cobrado ${ }^{18}$. Podría ser que los 100 pesos extra que pretendía cobrar Samaniego fueran destinados a pagar a sus oficiales, o bien aumentar sus beneficios, y que quisiera sacarlos de un comitente que había considerado el montante inicial como muy ajustado en precio. De hecho, según Borchart, Carondelet había adelantado para esta obra mil pesos, algo más de la cuarta parte gastada en materiales, otro cuarto para pagar a carpinteros, oficiales doradores y moledores de pintura y peones ${ }^{19}$. Quizás, una vez realizados los trabajos, Samaniego se dio cuenta de que podría haber obtenido más dinero por este encargo, y quiso corregirlo a posteriori, aunque con

${ }^{14}$ Ibidem. Los judíos eran "de 2 varas de alto, y los profetas variaban de $12 \frac{2}{3}$, los últimos, en pedestal, de $3 / 4$ ".

15 NAVARRO, José Gabriel: Contribuciones..., op. cit., p. 124.

${ }^{16}$ El cargo ya lo desempeñaba en 1800, como se recoge en la Guía del Estado Eclesiástico Seglar y Regular, de España en Particular, y de Toda la Iglesia Católica en General, para el Año 1800. Madrid, 1800, p. 302.

17 ANE, Fondo Especial, caja 169, tomo 396, no 33 (35). El documento está fechado el 24 de abril de 1802.

18 AHMRE (Archivo Histórico del Ministerio de Relaciones Exteriores del Ecuador), Libro de correspondencias varias que lleva el Sr. Barón de Carondelet, Presidente Gobernador y Comandante General de estas Provincias, año de 1802 (PQ. 1.4.4.2), ff. 47v-48.

${ }_{19}$ Véase el aparato crítico de VON HUMBOLDT, Alexander: Diarios de un viaje en la Audiencia de Quito. Quito, 2005, p. 113. 
resultado insatisfactorio, a tenor de las palabras de Carondelet. Este también tuvo desacuerdos en el pago al arquitecto de la catedral, Antonio García, como veremos a continuación. Eso sí, más allá de las desavenencias en relación al precio final, los comitentes hubieron de quedar muy satisfechos con el monumento realizado bajo la dirección de Samaniego ${ }^{20}$. En este sentido, el científico alemán Alexander von Humboldt consideraba este monumento "digno del mejor pintor de decoraciones de Europa", describiéndolo como "una hermosa perspectiva, de arcos adornados con las estatuas de profetas y al fondo un sarcófago debajo de un palio de plata" 21 . Las elogiosas palabras que Humboldt dedica a esta obra eran muestra, por un lado, del aprecio hacia el trabajo de un artista local al que comparaba con los mejores decoradores de Europa -y esto, viniendo de un personaje tan culto y viajero como él, debe ser valorado-, y por otra, de la voluntad de complacer al comitente -no tanto a la Iglesia cuanto al presidente Carondelet, con quien tenía amistad-.

Tras la vuelta a Popayán del arquitecto peninsular Antonio García, que había estado a cargo de las obras del templo hasta julio de 1803, Manuel Samaniego se encargó de la dirección de las mismas ${ }^{22}$. A pesar de los intentos por parte de Carondelet de retener a García en Quito, incluso con la oferta de una cátedra de dibujo y arquitectura, el español decidió regresar a Popayán ${ }^{23}$. Samaniego ya había demostrado en la década anterior su conocimiento del diseño de retablos -retablo mayor de Santa Clara ${ }^{24}$ - y recientemente de monumentos efímeros -el de la pro-

${ }^{20}$ El trabajo realizado por Samaniego y su obrador, según Garzón, tendría una concepción más académica. En el recibo que el pintor firmó en un contrato con la catedral de Quito fechado en 1802, además de los costos de materiales y los pagos a oficiales, incluyó específicamente su trabajo: "el que va desde diseños, delineaciones para bastidores, dirección de carpintería, el más fatigoso pintura de mis manos, dorados y armar la perspectiva". Véase GARZÓN M., Gloria María: "Situación de los talleres; gremios y artesanos. Quito, siglo XVIII", en I Simposio de Historia del Arte Artes "académicas" y populares del Ecuador. Cuenca, 1995, p. 22.

${ }^{21}$ VON HUMBOLDT, Alexander: Diarios de un viaje..., op. cit., pp. 113-114. En esta obra, las lámparas que iluminaban todo, las placas de plata maciza que reflejaban la luz y una música lúgubre "muy bien ejecutada en el fondo" tenían un efecto maravilloso.

${ }^{22}$ VARGAS, José María: "La Iglesia y el patrimonio cultural ecuatoriano", en Historia y Crítica del Arte Hispanoamericano. Real Audiencia de Quito (Siglos XVI, XVII y XVIII). Quito, 1999, p. 76. El arquitecto español, procedente de Popayán, había firmado un contrato para dirigir las obras de la catedral por un montante total de 3.500 pesos, comprometiéndose a estar presente en Quito "hasta llegar a la altura del arranque del cornisamiento". Véase NAVARRO, José Gabriel: "El arquitecto español don Antonio García y la Catedral de Quito", en Carondelet. Una autoridad colonial al servicio de Quito. Quito, 2007, p. 190.

${ }_{23}$ NAVARRO, José Gabriel: "El arquitecto español...”, op. cit., p. 196.

${ }^{24}$ De esta actividad se hacía eco VARGAS, José María: "Manuel Samaniego y Jaramillo", Revista de la Universidad Católica, 19, 1978, p. 44. 
pia catedral-, y ahora afrontaba la terminación de las obras previstas por García. Y lo hacía recomendado por el propio arquitecto que, en carta dirigida a Carondelet el 7 de julio de 1803, consideraba al artista quiteño "el más capaz de hacer ejecutar todos los diseños, de por mayor, y en su precisa medida le dejaré delineada con la instrucción necesaria para su práctica" ${ }^{25}$. Por lo tanto, García, que conocía bien al pintor, sabía de sus capacidades y se fiaba de él. Había tenido la ocasión de ver los resultados de su trabajo en el monumento del Jueves Santo, y también sus conocimientos relativos a arquitectura y retablística. Junto a ello, el arquitecto sabía de primera mano que Samaniego dirigía un gran obrador, y que era capaz de coordinar el trabajo de operarios muy diferentes para encargos provenientes de Quito y del exterior. Por todo ello, debía de tener plena confianza en la competencia de Samaniego para seguir fielmente sus indicaciones. No obstante, desde Quito se reclamó de nuevo la presencia de García para la conclusión de las obras, aunque un desacuerdo en relación a la retribución del arquitecto y también sus obligaciones laborales en Popayán lo impidieron. En abril de 1806, decía García desde Popayán que respecto a la catedral de Quito era necesario un trabajo de dirección de obra por la "impericia y pésima conducción de esos indios jornaleros [los operarios contratados para las obras de la catedral], con quienes es preciso tratar por no haber un Maestro de obra nacional"26. García mandó finalmente el diseño para la conclusión de la portada en 1806, según reconocía Carondelet en septiembre de ese año ${ }^{27}$. Las obras de la catedral concluyeron en junio de 1808, casi un año después del fallecimiento del gran impulsor de la empresa, el presidente Carondelet (Figura 1) ${ }^{28}$.

Ya en el siglo XIX fueron varios autores los que se hacían eco del trabajo de Samaniego en la catedral de Quito. Eso sí, se le atribuyeron algunos lienzos que en realidad correspondían a otro pintor quiteño: Bernardo Rodríguez. Por ejemplo, en el Plutarco del Joven Artista. Tesoro de Bellas Artes se relacionaba con Samaniego los cuadros de la Asunción de la Virgen (Figura 2), el Nacimiento del Niño Dios, la Adoración de los Reyes Magos, el Sacrificio de San Justo y San Pastor y algunos otros de historia sagrada ${ }^{29}$. Sabemos que al menos la Adoración de los Reyes Magos es de Bernardo Rodríguez, pues está firmada. Pero las concomitancias de estilo entre Samaniego y Rodríguez y el trabajo en común de estos pintores en esos años hicieron que se identificase como obra del primero. Para el inglés William Bennet Stevenson, que visitó la ciudad en 1810 -apenas una década después de que se hicieran las pinturas-, la catedral de Quito no atesoraba

${ }^{25}$ Reproducida en NAVARRO, José Gabriel: “El arquitecto español...”, op. cit., p. 196.

${ }^{26}$ Ibidem, pp. 201-202.

${ }^{27}$ El documento está reproducido en NAVARRO, José Gabriel: “El arquitecto español...", op. cit., p. 203.

28 VARGAS, José María: Manuel Samaniego y su Tratado de Pintura. Quito, 1975, p. 22.

${ }^{29}$ SUÁREZ, José Bernardo: Plutarco del Joven Artista..., op. cit., p. 352. 
muchas cosas de interés, salvo algunas pinturas realizadas por nativos de la ciu$\mathrm{dad}^{30}$. Se está refiriendo a las que habían pintado hacía pocos años Samaniego y Rodríguez. A mediados del siglo XIX, el diplomático brasileño Miguel Maria Lisboa señalaba que las pinturas de los arcos de la nave central de la catedral estaban pintadas al fresco por el célebre pintor nacional Samaniego, y que algunos de los cuadros eran de mérito ${ }^{31}$. Asimismo, indicaba que este pintor había sido maestro de Antonio Salas, y que murió en 1824, dejando entre otros los cuadros de Las cuatro estaciones en el museo -copiados de originales de Ludovico Boulogna- y otros en muchas casas particulares ${ }^{32}$. Es curioso que Lisboa indicara que, a excepción de Santiago y Samaniego, no le constase que ningún otro pintor fuera indio pues, de esta manera, para él uno y otro lo fueron, a diferencia de lo que opinaban el resto de autores de la época.

Humboldt también apreciaba el trabajo desarrollado por Samaniego en la catedral, ponderando los esfuerzos del barón de Carondelet por decorar con bellas pinturas lo que él consideraba un "mal local", tal como se refiere a la sede quiteña ${ }^{33}$. El científico alemán destacaba las bellas imágenes al fresco de los muros, y los hermosos cuadros de Samaniego en los altares, sobre todo en la Adoración de los Pastores. De ella valoraba la sencillez de la composición, del colorido, y una ejecución agradable, en la que se habían "desterrado los colores deslumbrantes e inharmónicos, estos dorados de las vestimentas que desfiguran la mayoría de las pinturas de Quito"34.

Además de estas pinturas, Samaniego y su obrador se encargaron de decorar las enjutas de los arcos de la nave central de la catedral con escenas de la vida de Cristo, pintadas al óleo sobre la pared ${ }^{35}$.

${ }^{30}$ STEVENSON, William Bennet: A historical and descriptive narrative of twenty years' residence in South America. Vol. II. Londres, 1825, p. 281.

${ }^{31}$ LISBOA, Miguel Maria: Relaçao de uma viagem a Venezuela, Nova Granada e Equador. Bruselas, 1866, p. 353. Este autor menciona también el museo que fue transferido del convento de los jesuitas al colegio de San Fernando del convento de Santo Domingo, y que tenía pinturas de Samaniego y Santiago (p. 368). En el primero figuraban los cuadros del "elegante Samaniego" y de Miguel de Santiago, "en los que brillan el genio que siempre ha distinguido a los habitantes de Quito", según reconocía en 1839 Vicente Rocafuerte. Véase VÁSQUEZ HAHN, María Antonieta: Luz a través..., op. cit., p. 223.

${ }_{32}$ LISBOA, Miguel Maria: Relaçao de uma viagem..., op. cit., p. 371.

${ }^{33}$ VON HUMBOLDT, Alexander: Diarios de un viaje..., op. cit., p. 113.

${ }^{34}$ Ibidem.

${ }^{35}$ NAVARRO, José Gabriel: Contribuciones..., op. cit., pp. 125-126. En cambio, en su obra póstuma indica que estas pinturas fueron realizadas al temple. Véase NAVARRO, José Gabriel: La pintura en el Ecuador..., op. cit., p. 141. 


\section{TRAS LA CAUSA POR ADULTERIO, JUNTO A SU MUJER EN EL COBRO DE UNA DEUDA}

Un capítulo interesante en la vida del matrimonio Samaniego-Jurado tras la causa por adulterio del pintor es el que los implicó en el cobro de una deuda contraída con ella, y que se sustanció en forma de demanda ejecutiva. Este episodio es paralelo en el tiempo al trabajo de Samaniego en la catedral como sustituto de Antonio García. En enero de 1803, Andrés de la Cuesta reconocía una deuda que su hermana, doña Juana de la Cuesta, había contraído en 1800 con María Manuela López, mujer legítima de Manuel Samaniego ${ }^{36}$. Aquí se nombra su esposa como María Manuela López, pero se trata de la misma Manuela Jurado López de Solís ${ }^{37}$. Y se dice que era vecina y del comercio. Según indicaba Andrés de la Cuesta, su hermana debía a la esposa de Samaniego 75 pesos desde junio de 1800. Ahora, el propio Andrés se comprometía a abonar esta cantidad, más el rédito del $6 \%$ correspondiente, en el plazo de dos años, sin pleito alguno y con las costas de la cobranza "si a ella diere lugar". Y lo hacía para que no se molestase a su hermana por este crédito. La cobranza del dinero adeudado no se habría tenido por qué dilatar en el tiempo si no fuera porque, una vez firmado el documento, fallecía el deudor, de tal manera que no se pudo cobrar. Por ello, el 13 de julio de ese año, Samaniego, como legítimo esposo de María Manuela López, hacía las gestiones pertinentes para que doña Jacinta Herrera, la viuda de Andrés de la Cuesta, satisficiese el monto adeudado en el tercer día, quedando citada si se negaba a ello ${ }^{38}$. Al día siguiente comparecía la viuda, que reconocía la autenticidad del vale firmado por su difunto esposo ${ }^{39}$. Tras ello, Samaniego pedía que se abonase la cantidad de 75 pesos dentro del segundo día, con apercibimiento de ejecución en fuerza de la obligación y reconocimiento. La firma del alcalde ordinario, don Ignacio de León y Báez, data de 6 de julio de $1805^{40}$. Por tanto, tuvieron que pasar dos años en estas gestiones, que se fueron prolongando aún más en el tiempo, pues la notificación a la viuda se hizo el 25 de enero de $1806^{41}$. El mes siguiente comparecía Samaniego para indicar que la deudora no había satisfecho

${ }^{36}$ ANE, Juicios, $1^{\text {a }}$ Notaría, caja 207, expediente 14-VII-1803, f. 1r. El reconocimiento de deuda por parte de Andrés de la Cuesta está firmado el 19 de enero de 1803. Se indicaba al final del mismo que la obligación se entendía solo por 70 pesos y los réditos correspondientes, pues 5 se habían cargado por equivocación "ut supra".

${ }^{37}$ En otra demanda para cobrar 300 pesos de Ramón de los Reyes y Carrasco, que se prolongó entre 1822 y 1823, la esposa aparece citada como María Manuela López Jurado. Véase FLORES CAAMAÑO, Alfredo: El artista don Manuel Samaniego y Jaramillo fue quiteño y escultor, a la vez que pintor. Quito, 1944, pp. 8-9.

${ }^{38}$ ANE, Juicios, $1^{\text {a }}$ Notaría, caja 207, Expediente 14-VII-1803, f. 2 r.

39 Ibidem, f. $2 \mathrm{v}$.

${ }^{40}$ Ibid., f. 3 r.

${ }^{41}$ Ibid., f. $3 \mathrm{v}$. 
el montante que se debía, por lo que solicitaba que se le pagasen los 70 pesos y los réditos vencidos del dinero "que se halla depositado en Caxas perteneciente a los bienes del d[ic]ho Cuesta" ${ }^{2}$. Tras estas gestiones, el escribano citaba el 12 de febrero a la deudora, y el 27 a Samaniego ${ }^{43}$. En la siguiente comparecencia de Samaniego -en la que aparece nombrado como don, y como marido de doña Manuela López Solís-, este solicita la cobranza de la deuda, pero señala que doña Jacinta Herrera no era la deudora, sino su marido, por lo que no había que proceder a su ejecución, sino al cobro del dinero depositado en las Cajas Reales para el pago de sus acreedores ${ }^{44}$. A continuación, sería Cristóbal Garcés, procurador a nombre de Samaniego, quien compareció ante el juez para intervenir. Había tenido noticia de que había un concurso de acreedores a estos bienes, y solicitaba pasar el expediente al asesor del concurso para que se pudiera proveer conforme a su petición ${ }^{45}$. A pesar de estas gestiones, la demanda se alargó todavía varios meses, pues a fines de enero de 1807 volvía Garcés a solicitar el cobro, señalando que la viuda no había contestado a su último escrito. El procurador lamentaba que sí se hubiera abonado lo adeudado a otros acreedores de la misma testamentaría ${ }^{46}$. El 1 de agosto, el escribano de la causa señalaba que todos los acreedores que habían comparecido demandando a la testamentaría de Andrés de la Cuesta mediante su oficio, ya estaban satisfechos. Finalmente, José Sánchez de Orellana ordenaba que se despachase libramiento para que Samaniego cobrase los 70 pesos con sus réditos y las costas de la instancia ${ }^{47}$. Cuatro años y medio después de iniciadas las gestiones, el 21 de agosto de 1807 se entregó la cantidad adeudada a Samaniego $^{48}$. El libramiento final fue de 128 pesos y 3 reales, reconociéndose la deuda de 75 pesos de principal, y no de 70 -como se señalaba en febrero de

42 Ibid., f. 4r.

${ }^{43}$ Ibid., f. 4v. El auto se firmaba el 6 de marzo por don Joaquín Ildefonso Laso, alcalde ordinario de Quito.

${ }^{44}$ ANE, Juicios, $1^{a}$ Notaría, caja 207, expediente 14-VII-1803, f. 5r. La provisión y firma por parte del alcalde ordinario se produjo el 14 de marzo. La siguiente comunicación a Samaniego se produjo el 2 de junio de 1806.

${ }^{45}$ ANE, Juicios, $1^{\text {a }}$ Notaría, caja 207, expediente 14-VII-1803, f. 6r. La provisión y firma por parte del alcalde ordinario se produjo el 26 de junio, mientras que el pedimento fue comunicado a doña Jacinta Herrera el 11 de julio.

46 ANE, Juicios, $1^{\text {a }}$ Notaría, caja 207, expediente 14-VII-1803, f. 7r. La provisión y firma por parte del alcalde ordinario se produjo el 21 de enero. El día siguiente citaría el juez al procurador, y el 6 de febrero cursó notificación a María Jacinta de Herrera, y luego citó a ambos el 19 de febrero.

${ }^{47}$ ANE, Juicios, $1^{\text {a }}$ Notaría, caja 207, expediente 14-VII-1803, f. 9r. La provisión y firma data de 18 de agosto de 1807. Finalmente, a 20 de agosto el escribano transmitió el decreto a Jacinta Herrera.

48 ANE, Juicios, $1^{\text {a }}$ Notaría, caja 207, expediente 14-VII-1803, f. 9v. 
$1806-{ }^{-49}$. El expediente es indicativo de lo dificultoso que podía ser la cobranza de una cantidad no excesivamente alta, teniendo en cuenta los ingresos de Samaniego por otras obras a las que hemos hecho referencia antes, y el gran desembolso que hizo por unas casas en el barrio de Santa Bárbara ${ }^{50}$. La obra que hizo para estas casas le supondría, en los años en que trataba de cobrar la cantidad adeudada por Andrés de la Cuesta, una querella por parte de doña Josefa Cañizares, su vecina. El pleito se prolongó entre 1802 y 1806, y en la inspección de la obra Samaniego contó con Antonio García, el arquitecto de la catedral ${ }^{51}$. Finalmente, el artista presentó un diseño de la cubierta de la pared, lo que da idea de sus conocimientos de arquitectura, y de que García debía de estar al tanto de los mismos.

\section{PROYECCIÓN DE SAMANIEGO EN LOS LUSTROS PREVIOS A LA INDEPENDENCIA}

Un año antes del Grito de Independencia de 1809, Manuel Samaniego estaba plenamente activo en la vida artística de Quito, desarrollando labores que excedían con mucho el trabajo de pintor. Por ejemplo, en 1808 constan pagos a Samaniego por su trabajo en las decoraciones del colegio de San Fernando por la llegada del presidente Ruiz de Castilla. En octubre de ese año se representaron durante cuatro noches obras de teatro a cargo de los estudiantes del colegio -concretamente Catón, Andrómaca, Zoraida y Araucana-. Consta un pago de 25 pesos a "D[o]n Manuel Samaniego por su trabajo en el Teatro", más "cien p[eso]s a D. Ramon Pizarro p[ar]a Samaniego" 52 . Asimismo, figura también un pago al pintor de 260 pesos "por su trabajo para las comedias". Según Vásquez Hahn, muy probablemente se trataría de los telones de fondo ejecutados para las piezas mencionadas más arriba ${ }^{53}$. De esta manera, esa faceta de Samaniego como pintor decorador, ya alabada por Humboldt, seguía explotándola después de marcharse de Quito el alemán.

Tras producirse el Grito de Independencia de 1809, Samaniego pudo continuar trabajando. Quien en los lustros anteriores había realizado encargos para la Iglesia y las élites civiles, tuvo ocasión de intervenir en otras obras públicas de

${ }^{49}$ En la regulación de costas aparecen desglosadas todas las cantidades por la demanda.

${ }^{50}$ En 1795, dos años antes de la causa por adulterio, el matrimonio pagaba a Manuel Suárez 3.225 pesos por esta propiedad. Véase VARGAS, José María: Manuel Samaniego..., op. cit., p. 28.

51 VARGAS, José María: Manuel Samaniego..., op. cit., p. 29.

52 VÁSQUEZ HAHN, María Antonieta: "El teatro insurgente en Quito", en La revolución en las tablas. Quito y el teatro insurgente 1800/1817. Quito, 2009, pp. 55, 57 y 65.

${ }_{53}$ Ibidem, p. 70. 
relevancia en esta época convulsa. En concreto, nos referimos al monumento fúnebre erigido en la iglesia de la Compañía el 3 de agosto de 1811 con motivo de las honras por los mártires del 2 de agosto de 1810. Tal como se indica en el documento, Samaniego fue contratado para dirigir y formar el cenotafio porque era el "más hábil pintor que tiene esta provincia y tal vez, toda la América, [...], sujeto de bellos conocimientos; y del más exquisito gusto" ${ }^{54}$. A comienzos de ese mismo año, ya había sido contratado para que "asee y hermosee la Sala General de la Academia" -es decir, la estancia en la que ya había estado trabajando en 1792-. En esta ocasión, el contrato ascendía a un total de 150 pesos, y se le daba expresamente las gracias por los 50 pesos "con que de su peculio ha protextado contribuir al adorno de dicho General" 55 .

Las razones esgrimidas para contratar a Samaniego para el cenotafio de la Compañía en 1811 no son las únicas palabras elogiosas hacia su figura en estos años. En 1810, época en la que vivió en Quito, William Bennet Stevenson consideraba al pintor, junto con Cortés y Solís, como el artista de más alta reputación del momento ${ }^{56}$. El científico natural de Popayán Francisco José de Caldas pensaba que si José Celestino Mutis hubiera visitado Quito, tanto Samaniego como Cortés y Rodríguez "habrían representado en el Nuevo Continente á Mengs, Lebrount y el Ticiano" ${ }^{57}$. El propio Caldas, que se lamentaba del estado de la pintura quiteña en su época, dominada por "eternos imitadores", sí ponderaba la figura de Samaniego. Señalaba que el artista pintaba con regularidad, "y aunque servil por timidez y por hábito, tiene gusto en la elección que hace, y mucho más en el colorido" 58 . A pesar de las virtudes que veía en el trabajo de Samaniego, Caldas se preguntaba “¿cuánto le falta para ser pintor?”. La losa de la imitación supondría para el científico payanés un impedimento para considerarlo un verdadero gran artista, aunque sí le reconocía su capacidad en la elección de la gama cromática.

En conclusión, Manuel Samaniego fue un artista polifacético que dominó el panorama artístico quiteño entre los últimos lustros del siglo XVIII y los primeros del siguiente. Tras el inconveniente que supuso su ingreso en la cárcel de Corte debido a la causa por adulterio, el artista retomó con impulso su actividad. Así,

${ }^{54}$ AH/MCE (Archivo Histórico del Ministerio de Cultura del Ecuador), Fondo JJC: ant. JJC 01150/ código actual: 01149. Le agradezco a doña María Antonieta Vásquez Hahn haberme proporcionado el dato.

55 VÁSQUEZ HAHN, María Antonieta: Luz a través..., op. cit., p. 187.

${ }^{56}$ STEVENSON, William Bennet: A historical and descriptive narrative..., op. cit., p. 298. El diplomático incluía a estos artistas entre los mestizos. Junto a Samaniego, está destacando al pintor José Cortés y al platero Luis López de Solís.

${ }^{57}$ DE CALDAS, Francisco José: "Discurso en elogio del doctor José C. Mutis", en Obras de Caldas. Bogotá, 1912, p. 103.

${ }^{58}$ DE CALDAS, Francisco José: "Viaje de Quito a Popayán”, en Obras de Caldas. Bogotá, 1912, p. 233. 
su obrador dio servicio a las élites religiosas y civiles de la ciudad, afrontando trabajos en pintura -obras individuales y series completas-, y dirigiendo trabajos de carácter arquitectónico, como la conclusión de la portada de la catedral diseñada por Antonio García. Tras independizarse de España los territorios de la Real Audiencia de Quito, Samaniego siguió al frente de encargos importantes, proyectando su trabajo como artista en ocasiones festivas hacia la nueva época. De esta forma, pocas semanas después de la batalla de Pichincha recibía el primer pago por la realización de un retrato de Simón Bolívar-concretamente, 6 pesos el 2 de junio, solo 9 días después de la batalla-. El retrato del Libertador se había encargado para que figurase en las fiestas en honor de Bolívar en el día de su onomástica, el 25 de octubre. Al día siguiente a la celebración terminaba de cobrar el resto por el retrato (otros 10 pesos), según consta en un recibo firmado por el artista y entregado al mayordomo de Propios de la ciudad ${ }^{59}$. Samaniego no pudo desarrollar su labor durante mucho más tiempo, pues fallecería en 1824. Fueron sus discípulos, a la cabeza de los cuales se situó Antonio Salas, quienes continuaron con el legado de este notable artista quiteño.

Fecha de recepción: 29 de octubre de 2018

Fecha de aceptación: 5 de febrero de 2019

${ }^{59}$ AMQ (Archivo Municipal de Quito), Cuentas de Propios, tomo 2 (1819-1837), f. 208. Le agradezco a doña María Antonieta Vásquez Hahn haberme proporcionado el dato. 


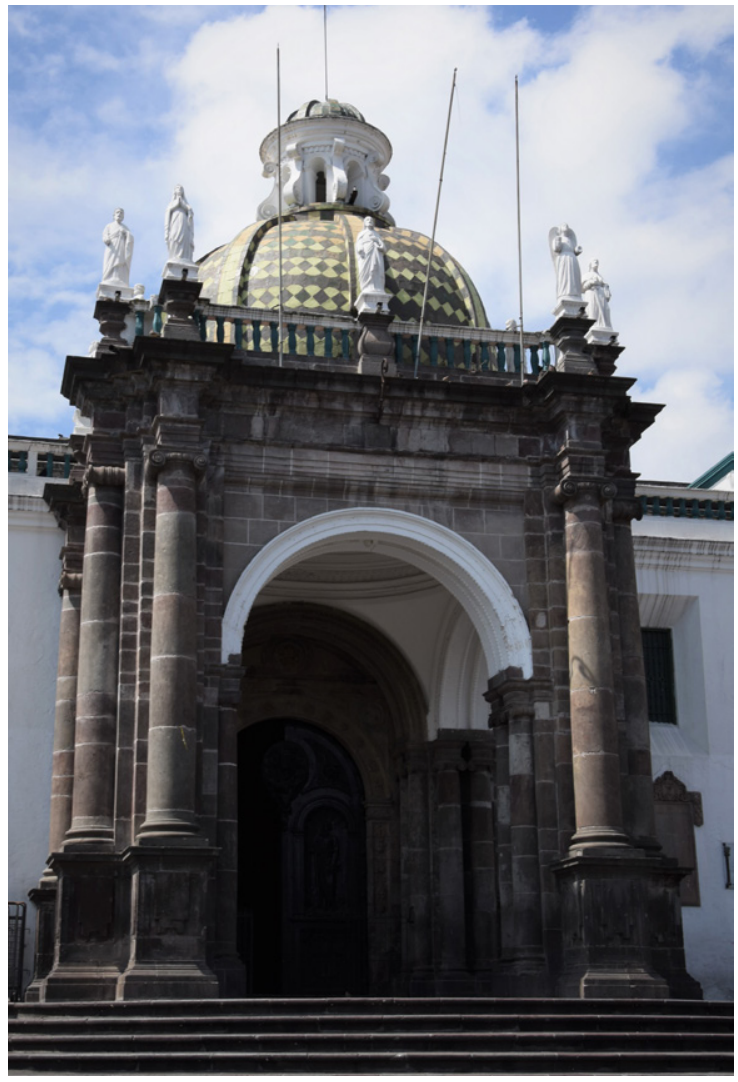

Figura 1. Antonio García, Portada lateral de la catedral de Quito, 1802-1808. Foto: Ángel Justo Estebaranz.

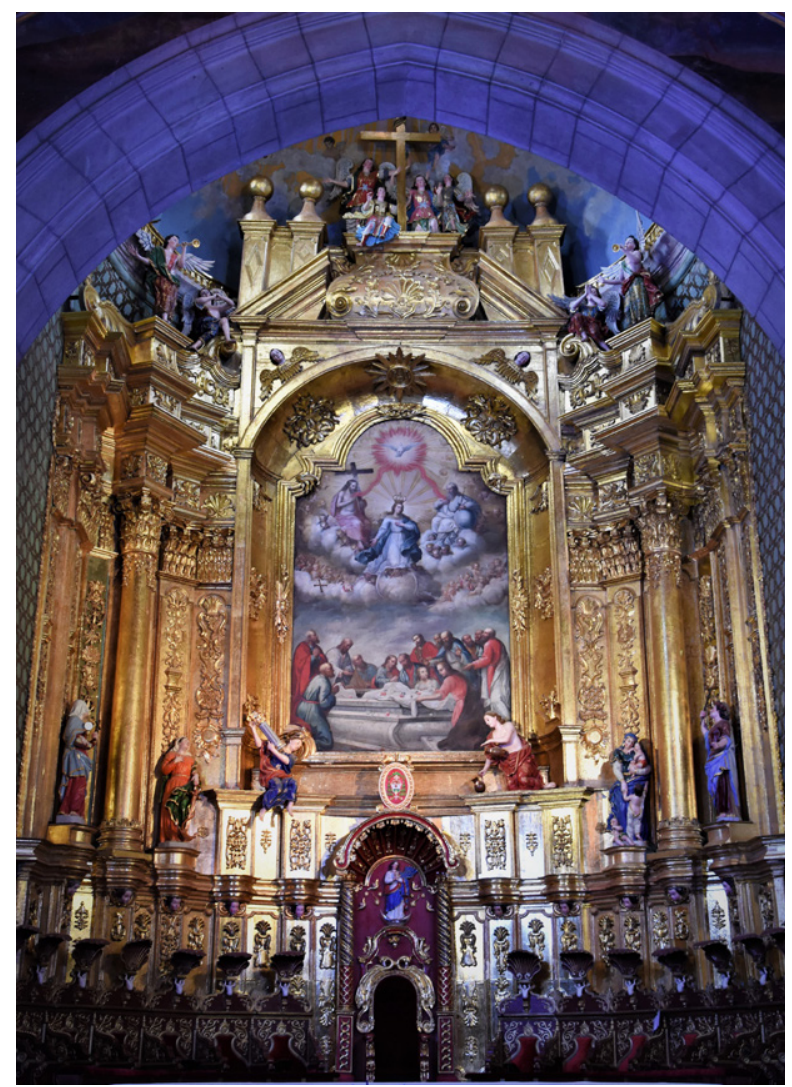

Figura 2. Retablo mayor de la catedral de Quito, con el lienzo de la Asunción de la Virgen de Manuel de Samaniego, hacia 1802. Foto: Ángel Justo Estebaranz. 